\title{
AC 2008-983: FUNDAMENTALS OF ENGINEERING EXAM GRADUATION REQUIREMENT
}

\section{Kirstie Plantenberg, University of Detroit Mercy}

Kirstie Plantenberg University of Detroit Mercy plantenk@udmercy.edu 


\title{
Fundamentals of Engineering Exam Graduation Requirement
}

\begin{abstract}
For many years, the University of Detroit Mercy (UDM) has required all engineering students to take a one credit Fundamentals of Engineering exam (FE exam) review class. Starting in 2005, Civil, Manufacturing and Mechanical engineering students were required to take the actual FE exam. By requiring the students to take the actual FE exam, the hopes were that UDM would give the student's a head start on the licensure process and the exam results would give UDM a meaningful objective and direct ABET assessment measure. Under this new graduation requirement, the FE review class has evolved. Structural and informational course changes have produced a steadily increasing FE Exam passing rate each successive year. This paper will explore the strategies used in offering a FE review course to students taking a full class load and little time to devote to a one credit class.
\end{abstract}

\section{Introduction}

For many years, the University of Detroit Mercy (UDM) has required that all engineering students take a one credit Fundamentals of Engineering exam (FE exam) review class. Passing the FE exam is usually the first of four steps needed to obtain a professional engineering license. The initial inception of the FE review course culminated in a mock FE exam and encouragement given to the students to take the actual FE exam. Under this course format only a small fraction of the students enrolled in the class took the real FE exam. Low exam participation was only one of many problems with this class format. The underlying problem was student motivation. The students felt that the class did not teach them anything new and with each student carrying an eighteen credit course load they felt that they had "more important" things to do. The class grade was not even a motivating factor. The course is only one credit and as long as they passed, the students were happy. The UDM engineering faculty all agreed that changes needed to be made.

Starting in 2005, the FE review class was restructured and Civil, Manufacturing and Mechanical engineering students were required to take the actual FE exam. The implementation of this new graduation requirement was motivated by two factors. First, the faculty agreed that it would be in the student's best interest to take the FE exam because it would give them a jump start on professional licensure. Second, as it stood, the FE review class was a very poor assessment measure. The students did not care about the class and therefore, the mock FE exam given at the end of the course gave very poor results. By requiring the students to take the actual FE exam, the hopes were that the student's motivation would increase and the exam results would give UDM a meaningful objective and direct ABET assessment measure.

Under this new graduation requirement, the FE review class has evolved. Continual changes have been made to the course based on FE exam results and comments coming out of an annually held student focus group. These structural and informational course changes have produced a steadily increasing FE Exam passing rate each successive year. This paper will explore the strategies used in offering a FE review course to students taking a full class load and little time to devote to a one credit class. 


\section{Background}

\section{What is the FE Exam?}

The Fundamentals of Engineering (FE) exam is a measure of minimum competency to enter the engineering profession ${ }^{[1]}$. Employers hiring recent engineering graduates often look to see if the applicant has successfully passed the FE exam. Passing the exam also demonstrates how serious you are about your engineering career.

The National Council of Examiners for Engineering and Surveying (NCEES) is the organization that oversees the development, distribution, and grading of the FE Exam, along with its counterpart, the Principles and Practice of Engineering (PE) exam. The FE Exam is a "limited reference exam," which means that the only reference material an examinee can use during the exam is the NCEES FE Reference Handbook ${ }^{[2]}$. This is a 258-page publication containing equations and data needed during the exam.

The FE exam is an 8-hour exam. It is broken up into two sessions: a 4-hour morning session and a 4-hour afternoon session. The morning session contains 120 general engineering questions in the areas of: Mathematics, Engineering Probability and Statistics, Chemistry, Computers, Ethics and Business Practices, Engineering Economics, Engineering Mechanics (Statics and Dynamics), Strength of Materials, Material Properties, Fluid Mechanics, Electricity and Magnetism, and Thermodynamics. Each question is multiple choice and, on average, should be solved in 2 minutes. The afternoon session contains 60 questions and the examinee may choose to answer questions in one of the following seven modules: Chemical, Civil, Electrical, Environmental, Industrial, Mechanical, and General engineering. Each question is multiple choice and, on average, should be solved in 4 minutes.

\section{What is Engineering Licensure?}

According to the NCEES (National Council of Examiners for Engineering and Surveying), "Licensure is the mark of a professional". Becoming licensed as a professional engineer (P.E.), shows that your engineering knowledge is up to a recognized standard, and it provides career options and opportunities that might not be available otherwise ${ }^{[3]}$. Licensure is a designation that sets you apart from other engineers, enhances your career potential, and frees you to make important career decisions such as starting your own business or consulting. Only licensed professionals are allowed to offer their services to the public and sign and seal plans for the public. These requirements and high standards help protect the public's safety and welfare.

The licensure procedure and requirements varies slightly from state to state, but in general, the following four steps must be completed before you may apply for a professional engineering license (as listed by the NCEES ${ }^{[3]}$ ).

Step 1) FE Exam: An applicant must take and pass the Fundamentals of Engineering (FE) exam. The student must have at least a senior standing to take the FE exam. Once an 
applicant has passed the FE exam, they are classified as an Engineering Intern (EI) or Engineer-in-Training (EIT).

Step 2) Graduation: The applicant must graduate from an ABET-accredited engineering program at a college or university.

Step 3) Work Experience: After passing the FE exam and graduating, the EI must gain actual work experience. The duration and type of work experience required depends on the state in which the license is going to be acquired. The requirements are available through a state's licensing board. The requirement usually includes a four year internship.

Step 4) PE Exam: Once the EI has obtained the appropriate experience required, he/she must take and pass the Principles and Practice of Engineering (PE) exam.

After successfully completing the four steps, the engineer is eligible for licensure by their state's licensing board. Once licensure is granted, the engineer is known as a "professional engineer", or P.E. A professional engineering license (P.E.) allows engineers to legally represent themselves to the public as an engineer, offer consulting engineering services to private and public entities, and perform engineering design or construction on public works.

\section{Course Description}

Professional World of Work 303 (PWOW3) is a course designed to prepare and motivate University of Detroit Mercy (UDM) engineering students to take and pass the Fundamentals of Engineering (FE) exam. The FE exam is usually the first step towards professional licensure. The course description as given in UDM's undergraduate course catalog is:

This course focuses on preparation for the Fundamentals of Engineering Examination, which is the first step toward professional licensure. Students are provided refresher sessions in: mathematics, chemistry, statics, dynamics, science of materials - structure of matter, thermodynamics, fluid mechanics, economics, principles of electrical engineering, and mechanics of materials.

PWOW3 is a 1-credit 15-week long class. It is team taught by faculty from various engineering and science departments. It is a required course for all engineering students of every discipline. UDM offers degrees in Civil, Electrical, Manufacturing and Mechanical engineering. PWOW3 has two sections. One section is for the Electrical engineering students and the other section is for all other engineering disciplines. Each section covers different topics and has different course requirements. The major difference being that the Electrical engineering students are not required to take the actual FE exam. From here on out all information presented about the course will be in reference to the section that is taught to the Civil, Manufacturing and Mechanical engineering students.

\section{Course Structure and Requirements}

Passing PWOW3, and thus being able to graduate, requires that the student obtain a passing grade in the class and take the actual FE exam, or take and pass the actual FE exam. The 
class requires that each student complete a set of online homework and take an in class quiz for each review topic.

The structure of PWOW3 has gone through many changes through the years. Each change has been designed to increase information retention, student motivation, and availability of direct ABET assessment data. The initial offerings of PWOW3 meet once a week. The course started with a pre-test and culminated in a mock FE exam. The student's grade depended on attendance and their grades on the two exams. Under this course format student motivation was low, assessment data was limited and only a small fraction of the students enrolled in the class took the real FE exam. After many discussions, it was decided to make taking the real FE exam a course requirement. The faculty felt that this would motivate the students to study, give them a head start on the licensure process, and give UDM's engineering programs direct assessment data. Since the FE graduation requirement was implemented, the structure of course has evolved based on the successes and failures of the previous offerings.

The current offering of PWOW3 meets for 50 minutes twice a week (Monday and Friday) for 15 weeks. On Monday an instructor will come and review a topic, give each student a packet of review information, and assign online FE style homework problems that are due the following Friday. The homework problems are posted as an online quiz on Blackboard. Online homework allows the student to get immediate feedback on what problems they got correct or incorrect. On Friday, the same instructor answers questions about the online homework and solves any problem requested. The following Monday, the students are given a short quiz directly based on the homework followed by the next review session. Figure 1 illustrates the class structure described above. This routine continues for 14 weeks followed by taking the actual FE exam. After the students have taken the FE exam, they come back and participate in a course survey focus group discussion. During this time, the students are asked to comment on their experience and what they think could be done to strengthen the course content, structure and implementation.

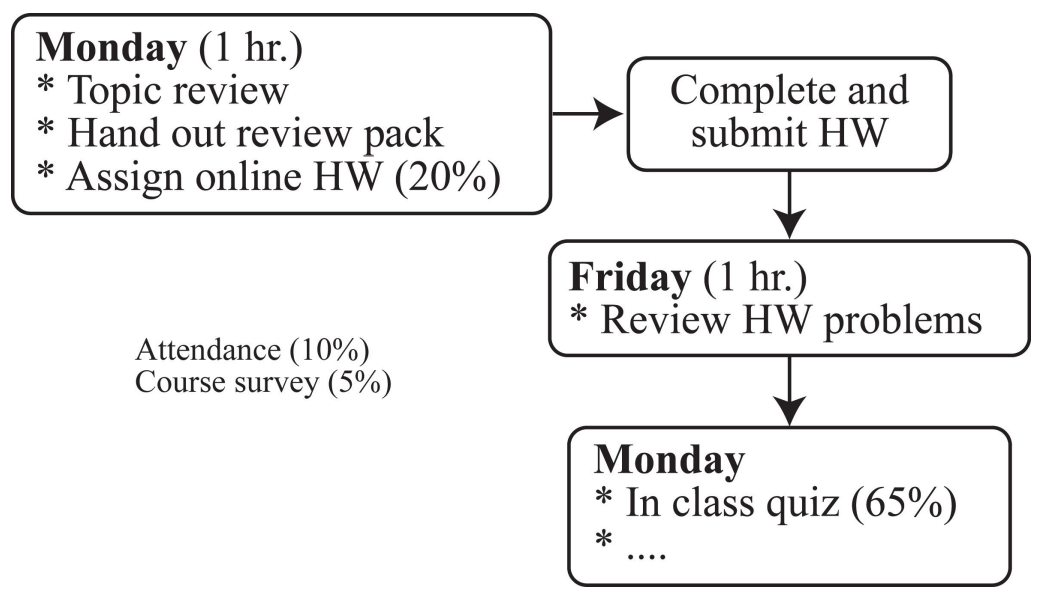

Figure 1: PWOW3 class structure.

The student's course grade is based on: attendance (10\%), online homework (20\%), quizzes $(65 \%)$, course survey $(5 \%)$ and verification of FE exam registration. Table 1 gives the 
scheduling for each review topic covered in the Winter 2007 offering of PWOW3. The order of the topics might not seem an obvious choice; however, there were two concerns that needed to be addressed: faculty availability and the Electrical engineering (EE) section of PWOW3. All students from both sections of PWOW3 combine into one class for the first half of the semester. After spring break, the EE's break off and cover more EE specific topics while the other engineering disciplines continue to cover the topics listed.

\begin{tabular}{|l|l|l|}
\hline Date & Monday & Friday \\
\hline Jan. 8-12 & Introduction to State Licensure & Course Overview, Computers \\
\hline Jan. 15-19 & $\begin{array}{l}\text { Martin Luther King Day } \\
\text { (No Class) }\end{array}$ & Computer Problems \\
\hline Jan. 22-26 & Chemistry & Chemistry Problems \\
\hline Jan. 29- Feb. 2 & Mathematics & Mathematics Problems \\
\hline Feb. 5-9 & $\begin{array}{l}\text { Engineering Probability and } \\
\text { Statistics }\end{array}$ & $\begin{array}{l}\text { Engineering Probability and } \\
\text { Statistics Problems }\end{array}$ \\
\hline Feb. 12-16 & Statics & Statics Problems \\
\hline Feb 19-23 & Thermodynamics & Thermodynamics Problems \\
\hline Feb. 26- March 2 & Electricity and Magnetism & $\begin{array}{l}\text { Electricity and Magnetism } \\
\text { Problems }\end{array}$ \\
\hline March 5-9 & Spring Break (No Class) & \\
\hline March 12-16 & Dynamics & Dynamics Problems \\
\hline March 19-23 & Fluid Mechanics & Fluid Mechanics Problems \\
\hline March 26-30 & Strength of Materials & Strength of Materials Problems \\
\hline April 2-6 & Ethics and Business Practices & Easter Break \\
\hline April 9-13 & Material Properties & Material Properties Problems \\
\hline April 16-20 & Engineering Economics & Engineering Economics Problems \\
\hline April 21 & Actual FE Exam & \\
\hline April 25 & Course Survey & \\
\hline
\end{tabular}

Table 1: PWOW3 topics and scheduling.

\section{Discussion and Results}

Successes

The key to running a successful FE review class with only 1-credit hour is student motivation. The students must take it upon themselves to study out side of class. There are several steps that we have taken to sure up student motivation. During the first class, we bring in a practicing engineer to talk about the licensure process and its importance. During the Winter 2007 offering of the course, we brought in a member of the Engineering Society of Detroit (ESD) and a member of the Michigan State Licensing board. After the guest speaker(s) became part of the class, student motivation increased and the number of complaints about the amount of course work required decreased. Another motivational tool is the exam fee reimbursement program. If a student takes and passes the FE exam, the registration fee (currently \$155) is reimbursed by UDM's college of Engineering and Science. 
Getting the students to complete the assigned online homework was a challenge. We successfully dealt with this by making the homework worth $20 \%$ of the course grade and based the respective quizzes (65\% of the grade) directly on the homework. An individual in class quiz is generated by randomly choosing between 2 and 5 online homework problems and changing a number here or there so that the answer changes. The wording of the problem does not change. By doing this, it tells the students that completing and understanding the homework is very important and in a sense is worth $85 \%$ of your grade. Therefore, creating the homework is not just a matter of randomly selecting some problems out of a book. A good deal of thought goes behind each set of homework problems. There is a balance that needs to be struck. The number of problems needs to be sufficient to cover the subject, but not so many that the student gets overloaded and looses his/her motivation. We start by looking at the sub-topics listed in the Fundamentals of Engineering examination specifications and the equations given in the FE reference handbook ${ }^{[2]}$. We then create at least one problem for each sub-topic/equation. Many times 2 or 3 problems are created for the more important sub-topics. For example, the sub-topics and equations for Statics are given in Table 2.

\begin{tabular}{|l|l|}
\hline $\begin{array}{l}\text { Sub-topics from the FE } \\
\text { specifications }\end{array}$ & Equations listed in the FE reference handbook \\
\hline Resultants of force systems & Resolution of a force, and Resultant of a force system \\
\hline Centroid of area & Centroids of masses, areas, lines and volumes \\
\hline Concurrent force systems & Concurrent forces \\
\hline Equilibrium of rigid bodies & Systems of forces \\
\hline Frames and trusses & Statically determinant trusses \\
\hline Area moments of inertia & Moment of inertia \\
\hline Friction & Friction, Screw thread and Belt friction \\
\hline
\end{tabular}

Table 2: Sub-topics and equations for Statics.

A recently implemented success is the end of semester focus group discussion with the students. Many of the course structural changes have come directly from the suggestions made by students during this session.

\section{Challenges}

The course has gone through several changes based on student comments about what did not work. Scheduling the quizzes has been one of the biggest problems. Initially, the class meet once a week for $1 \frac{1 / 2}{2}$ hours. Under this format the students where responsible for reviewing the supplied review material independently, completing the online homework and then attending a problem review session immediately followed by the quiz. This format did not give the students enough time to digest the answers to their questions before having to take the quiz. To elevate this problem, we moved the quiz to the following week. This created even more problems. The students did not like having to study for a quiz and at the same time review the next topic and complete homework. During the Winter 2006 offering of the class a special 15 minute quiz section was added to the class that occurred a few days after the problem review session. This allowed the students to digest the quiz information and still allowed them enough time to review 
and complete the homework for the new topic. This was a workable solution; however, we felt that the students would benefit from a topic as well as a problem review. Currently the class meets twice a week for 50 minutes. The topic is reviewed on Monday, the homework problems are reviewed on Friday, and then the quiz is given at the beginning of the following Monday's class.

Initially, the online homework was set to allow multiple attempts. The thought behind allowing multiple attempts on the homework was that it would give the students an opportunity to see which problems they got wrong, re-solve them and try again. However, this failed miserably. The students would just try every combination until they received a correct answer. Now the homework is set to allow a single timed attempt.

A major challenge in offering a 1-credit FE review class is available time. With limited time, there is only time to review morning exam topics and no time to review the afternoon session subjects. Comments coming from last years focus group led us to believe that the students would be in favor of added more contact hours to the course with out adding credit hours. Therefore, the idea of adding some Saturday class meetings is being considered. These Saturday meetings would not be required, cover afternoon session topics and only occur if a set number of students commit to being their.

Results

The FE exam graduation requirement was implemented in 2005. Since this time, we have, obviously, seen a significant increase in the number of students taking the actual FE exam. Before this time, an extremely small number of UDM students took the FE exam. Table 3 shows the number and constituency of the students taking the FE exam under both course formats.

\begin{tabular}{|l|l|l|l|l|l|l|}
\hline PM Exam topic & $\mathbf{2 0 0 2}$ & $\mathbf{2 0 0 3}$ & $\mathbf{2 0 0 4}$ & $\mathbf{2 0 0 5}$ & $\mathbf{2 0 0 6}$ & $\mathbf{2 0 0 7}$ \\
\hline Chemical & 0 & 0 & 0 & 1 & 0 & 0 \\
\hline Civil & 3 & 1 & 0 & 1 & 7 & 3 \\
\hline Electrical & 1 & 0 & 0 & 0 & 1 & 0 \\
\hline Environmental & 0 & 0 & 0 & 0 & 1 & 1 \\
\hline General & 1 & 1 & 1 & 16 & 1 & 7 \\
\hline Mechanical & 1 & 0 & 1 & 5 & 12 & 13 \\
\hline Total & $\mathbf{6}$ & $\mathbf{2}$ & $\mathbf{2}$ & $\mathbf{2 3}$ & $\mathbf{2 2}$ & $\mathbf{2 4}$ \\
\hline
\end{tabular}

Table 3: Number of students taking the FE exam.

The pilot class, in 2005, had its ups and downs. A lot of kinks needed to be worked out. Changes were made to the 2006 offering of the class; however, further improvements were needed. The passing rates for those years were not what we had expected. Based on student feedback, major improvements were made to the 2007 offering of the class and the passing rate significantly increased. Figure 2 shows UDM's passing rates for 2002 through 2007. Table 4 lists the national passing rates for first time takers sitting for the April 2007 FE exam along with UDM's passing rate for the same exam. The national passing rates were obtained from the NCEES Annual Report ${ }^{[4]}$. When viewing the passing rates, it is important to remember that the 
majority of people that take the FE exam take it because they are prepared and expect to pass. Our students are forced to take the FE exam ready or not. Given that, we feel that our students did exceptionally well. This year's offering, thus far, is running very smooth and we expect a similar or increased passing rate.

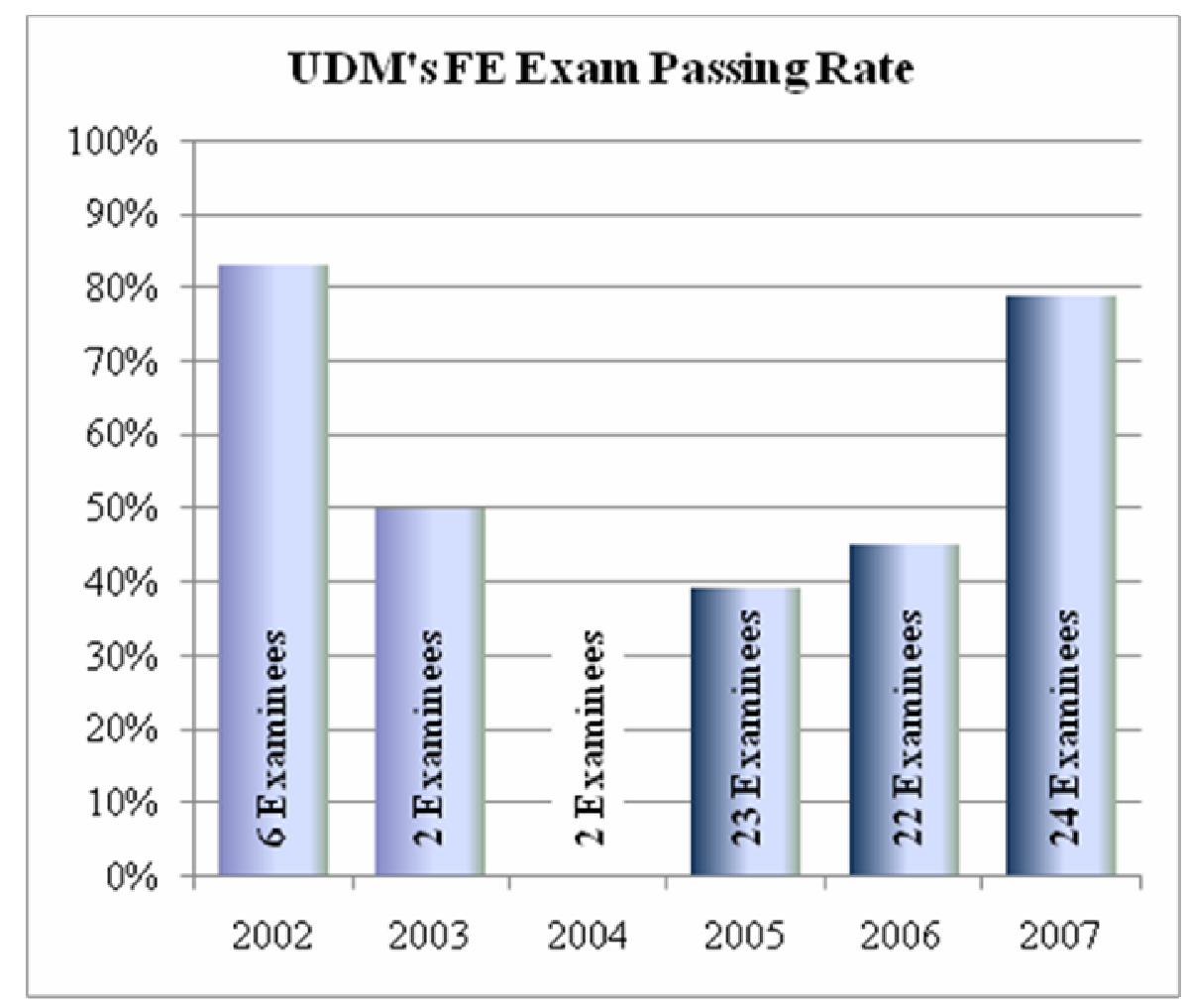

Figure 2: UDM's Fundamentals of Engineering Exam Passing rate per year.

\begin{tabular}{|l|l|l|}
\hline PM Module & National & UDM \\
\hline Civil & $76 \%$ & $100 \%$ \\
\hline Environmental & $81 \%$ & $100 \%$ \\
\hline General & $77 \%$ & $71 \%$ \\
\hline Mechanical & $80 \%$ & $77 \%$ \\
\hline
\end{tabular}

Table 4: FE exam passing rates for the April 2007 exam.

\section{Conclusion}

The University of Detroit Mercy (UDM) requires that all of its engineering seniors take a Fundamentals of Engineering (FE) exam review class. The engineering departments have managed to create an overall successful review class that requires all Civil, Manufacturing and Mechanical engineering students take the actual FE exam. This has resulted in a high UDM FE exam participation rate and a steadily increasing passing rate. 
Overall, the FE exam graduation requirement has been a success for both the students and the university. UDM has managed to steer the majority of its graduates on to the path of professional licensure and UDM now has a completely objective and direct ABET assessment measure. The new requirement has not seemed to affect how students view UDM's engineering programs. However, given the amount of work required for this course, it has put quite a burden on the students. At an 18-credit course load, work increased in one class has to come out of another class.

Improvements to the class will continue to be made. The informational review packs and homework problems will continue to evolve based on the subject specific FE exam results and student feedback. Currently, the class structure and scheduling seems to be an effective arrangement.

\section{References}

[1] National Council of Examiners for Engineering and Surveying (NCEES) http://www.engineeringlicense.com/feexam/

[2] National Council of Examiners for Engineering and Surveying (NCEES), "Fundamentals of Engineering Supplied-Reference Handbook $8^{\text {th }}$ Ed.", 2008, ISBN: 1-932613-30-8

[3] National Council of Examiners for Engineering and Surveying (NCEES), www.ncees.org

[4] NCEES Annual Report 2006-2007. 